\title{
Effects of polymyxin B on clinical signs, serum TNF-a, haptoglobin and plasma lactate concentrations in experimental endotoxaemia in sheep
}

\author{
Ali Hajimohammadi, Khalil Badiei, Parviz Kheibari, Meherdad Pourjafar, Aliasghar Chalmeh \\ Department of Clinical Sciences, School of Veterinary Medicine, \\ Shiraz University, Shiraz, 71345-1731, Iran \\ hajimohammadi@shirazu.ac.ir
}

Received: September 18, 2017

Accepted: February 16, 2018

\begin{abstract}
Introduction: The experiment evaluated the effects of intravenous administration of polymyxin B on experimental endotoxaemia in sheep. Material and Methods: Twenty clinically healthy fat-tailed sheep were randomly divided into: a group treated with $6,000 \mathrm{U} / \mathrm{kg}$ of polymyxin B, a group at $12,000 \mathrm{U} / \mathrm{kg}$, and positive and negative controls. Endotoxaemia was induced by intravenous administration of lipopolysaccharide (LPS) from E. coli serotype O55:B5 at $0.5 \mu \mathrm{g} / \mathrm{kg}$. polymyxin was infused intravenously along with $2.5 \mathrm{~L}$ of isotonic intravenous fluids at $20 \mathrm{~mL} / \mathrm{kg} / \mathrm{h}$. The positive control group received LPS and $2.5 \mathrm{~L}$ of isotonic fluids, the negatives receiving just $2.5 \mathrm{~L}$ of isotonic fluids. Clinical signs were evaluated before and at 1.5, 3, 4.5, 6, 24, and $48 \mathrm{~h}$ after LPS administration. Blood was also sampled at the denoted hours and serum haptoglobin, tumour necrosis factor- $\alpha$ (TNF- $\alpha$ ), and plasma lactate concentrations were assayed. Results: The serum concentration of TNF- $\alpha$ in the positive control group increased significantly up to $48 \mathrm{~h}$ after LPS administration. The concentration of TNF- $\alpha$ was significantly different from those of the polymyxin B and positive control groups from 3 to $48 \mathrm{~h}$; also, the concentrations of haptoglobin at different times in the polymyxin groups were lower than those of the positive control group and were significant at hours 3 to 48 ( $\mathrm{P}<0.05)$. Following the LPS administration, haptoglobin and TNF- $\alpha$ concentrations changed without significant difference between the two polymyxin B groups. Conclusion: Polymyxin B (6,000 U/kg) restrained blood lactate concentrations. Furthermore, it significantly improved the clinical signs in endotoxaemic animals, including rectal temperature and heart and respiratory rates. Polymyxin B may be an antiendotoxic in fat-tailed sheep.
\end{abstract}

Keywords: sheep, lipopolysaccharide, polymyxin B, clinical signs, inflammatory biomarkers.

\section{Introduction}

Gram-negative bacteria, especially Escherichia coli, play a major role in the development of endotoxaemia among sheep and other livestock $(8,20,34)$. Current data suggest that endotoxin is liberated and enters general circulation during bacteriolysis or periods of rapid growth. Endotoxaemia is the usual form of toxaemia, which leads to multiple organ dysfunctions such as cardiovascular, respiratory, and haemostatic and biochemical changes, may eventually result in death, and is a significant cause of mortality in farm animals. Lipopolysaccharides (LPS), also known as endotoxins, are an integral part of the outer membrane of the cell wall in Gram-negative bacteria (28). LPS stimulate many adverse systemic reactions and trigger the release of proinflammatory mediators $(27,32)$. Over the past years, several therapeutic strategies have been designed for treatment and prevention of endotoxaemia. Therapies suggested for Gram-negative sepsis and septic shock involve utilisation of antibiotics to control the infection and intensive care support to correct the underlying dysfunctions in circulatory, ventilatory, and other organ systems. However, only a few of these therapies have been proved to be effective.

One of the approaches used for the treatment of endotoxaemia is inactivation of LPS, which can be attained by neutralisation of endotoxin. The inactivation goal may be achieved through administration of polymyxin $\mathrm{B}$, which is a bactericidal antibiotic belonging to the group of peptide antibiotics that has long been known to specifically target LPS and provide protection against LPS lethality (4). Lipid A is the biologically active portion of LPS. Polymyxin B has the 
capacity to bind with high affinity to this active portion of LPS and neutralise its biological activity, which leads to restriction of the proinflammatory cytokine cascade $(14,19)$. Treatment with polymyxin $\mathrm{B}$ to attenuate clinical endotoxaemia is frequently used in adult horses for conditions such as strangulating intestinal lesions, pleuropneumonia, and postpartum metritis, with beneficial effects (34). The effects of intravenous applications of pentoxifylline and polymyxin B on the acute-phase-response to Escherichia coli endotoxin in dwarf goats have been evaluated (29). However, no study has been carried out on the clinical impact and anti-inflammatory effects of polymyxin B alone on endotoxaemia in sheep. The present study has evaluated the clinical manifestations and some circulating inflammatory biomarkers, including haptoglobin, TNF- $\alpha$, and lactate, in an ovine experimental model in which endotoxaemia was induced by LPS of Escherichia coli serotype O55:B5.

\section{Material and Methods}

Animal care. Twenty clinically healthy fivemonth-old Iranian fat-tailed sheep, with an average body weight of $20 \pm 1.5 \mathrm{~kg}$, were randomly selected for the project. All sheep had normal physical examination results and fibrinogen concentrations and complete blood count (CBC) results. Four weeks before the start of the experiments, each sheep was treated orally with albendazole (15 mg/kg; Dieverm 600, Razak Pharmaceutical Co, Iran) and subcutaneously with ivermectin $(0.2 \mathrm{mg} / \mathrm{kg} ; 1 \%$ Erfamectin, Erfan Pharmaceutical Co, Iran) to control probable internal and external parasites. All sheep were maintained in open-shed barns with free access to water, food, and shade. The ration included mainly alfalfa hay, corn silage, corn, and barley. At the beginning of the study the animals were not fasted. Subsequently, sheep were randomly assigned into four equal experimental groups comprising animals treated with polymyxin $\mathrm{B}$ at a dose of $6,000 \mathrm{U} / \mathrm{kg}(\mathrm{BI})$ or $12,000 \mathrm{U} / \mathrm{kg}$ (BII), negative controls, and positive controls.

Chemicals and drugs. Phenol-extracted LPS from Escherichia coli serotype O55:B5 (product no. L2880, Sigma-Aldrich, Germany) were used at a dose of $0.5 \mu \mathrm{g} / \mathrm{kg}$ as a source of endotoxin, inducing endotoxaemia in sheep (36). The endotoxin was diluted in sterile phosphate buffered saline (PBS, pH 7.4, Sigma-Aldrich, Germany) and then divided into 15 equal doses each containing $0.5 \mu \mathrm{g} / \mathrm{kg}$ of the endotoxin, and stored at $-80^{\circ} \mathrm{C}$ until LPS administration $(5,6)$. Polymyxin B $(6,000$ and $12,000 \mathrm{U} / \mathrm{kg})$ was intravenously administered to the sheep as a bolus according to an established experimental design (32). The intravenous fluid used was $5 \%$ dextrose plus $0.45 \%$ sodium chloride (Shahid Ghazi Pharmaceutical Co., Iran).

LPS administration and treatment of endotoxaemia. A $5.1 \mathrm{~cm}$ rinsing catheter was secured in the left jugular vein and used for blood samplings and endotoxin and drug infusions. All sheep underwent a complete physical examination before and at 1.5, 3, 4.5, 6, 24, and $48 \mathrm{~h}$ after LPS injection. Clinical variables including rectal temperature and heart and respiratory rates were monitored during the experiments. Thawed LPS was diluted in $250 \mathrm{~mL}$ of normal saline and then infused intravenously at the rate of $10 \mathrm{~mL} / \mathrm{kg} / \mathrm{h}$. Fluid therapy was performed in all experimental groups over a 30 -min period after LPS injection by $5 \%$ dextrose plus $0.45 \%$ sodium chloride at the rate of $20 \mathrm{~mL} / \mathrm{kg} / \mathrm{h}$. Immediately after the end of LPS infusion, polymyxin B was used along with the fluid therapy over $60 \mathrm{~min}$. Polymyxin B was infused separately at $6,000 \mathrm{U} / \mathrm{kg}$ or $12,000 \mathrm{U} / \mathrm{kg}$ doses. Five sheep were randomly selected as the positive control group and received only LPS and an equal volume of saline solution (IV) instead of drugs. Similarly, another five sheep were randomly selected as the negative control group and received just intravenous fluid without any drugs or LPS.

Blood sampling and biochemical assays. Blood samples of all sheep were collected using fixed rinsing catheters before and at 1.5, 3, 4.5, 6, 24, and $48 \mathrm{~h}$ after LPS injection and kept in plain anticoagulant-containing (potassium oxalate/sodium fluoride) tubes. Immediately after collections, sera and plasma were separated by centrifugation at $3,000 \times \mathrm{g}$ for $10 \mathrm{~min}$ and stored at $-22^{\circ} \mathrm{C}$ until being assayed. Clinical variables including heart rate, respiratory rate, and rectal temperature were recorded at the same time as blood sample collection.

Haptoglobin, TNF- $\alpha$, and lactate determination. Serum haptoglobin $(\mathrm{Hp})$ was measured according to the preservation of peroxidase activity of haemoglobin procedure, which is directly proportional to the amount of Hp (Tridelta Development Ltd., Ireland). The lowest measuring interval of this test has been determined as $15.6 \mathrm{mg} / \mathrm{L}$ by the manufacturer. Tumour necrosis factor- $\alpha$ (TNF- $\alpha$ ) was measured in serum by a solid phase sandwich ELISA (product no. AbC 606 Eurobio AbCys S.A., France). For TNF- $\alpha$, a cut-off point of $129 \mathrm{ng} / \mathrm{L}$ represented $96 \%$ sensitivity and $93 \%$ specificity. Measurement of lactate was performed in plasma taken from potassium oxalate/sodium fluoride anticoagulant, using a Lactate Assay Kit considering the guidelines provided by the manufacturer (lactate monoliquid, product no. BXCO622, Biorexfars, Iran). The lactate had a sensitivity of $90 \%$ and specificity of $87 \%$.

Statistical analyses. Data were expressed as mean tstandard deviation (SD). To compare mean concentrations of different parameters among different experimental groups, over similar periods, one-way ANOVA with an LSD post-hoc test was used. As a multifactorial ANOVA test, a repeated measures ANOVA was used to estimate the trend change of each parameter in separate groups from hour 0 to hour 48 . In this test, the time was considered as a covariable and the changing pattern of each parameter was evaluated during the study. A paired samples $t$-test was used to 
determine the differences between two different time periods. The level of significance was set at $\mathrm{P}<0.05$. Statistical analysis was performed using SPSS software (SPSS for Windows, version 11.5, SPSS Inc, USA). Results by parameter are presented in Table 2.

\section{Results}

Clinical variables. Clinical manifestations observed after LPS administrations were depression, incoordination, tremors, rapid laboured breathing, tachycardia, groaning, increased body temperature, anorexia, diarrhoea, and prostration. The results of monitored clinical variables are presented in Fig. 1.
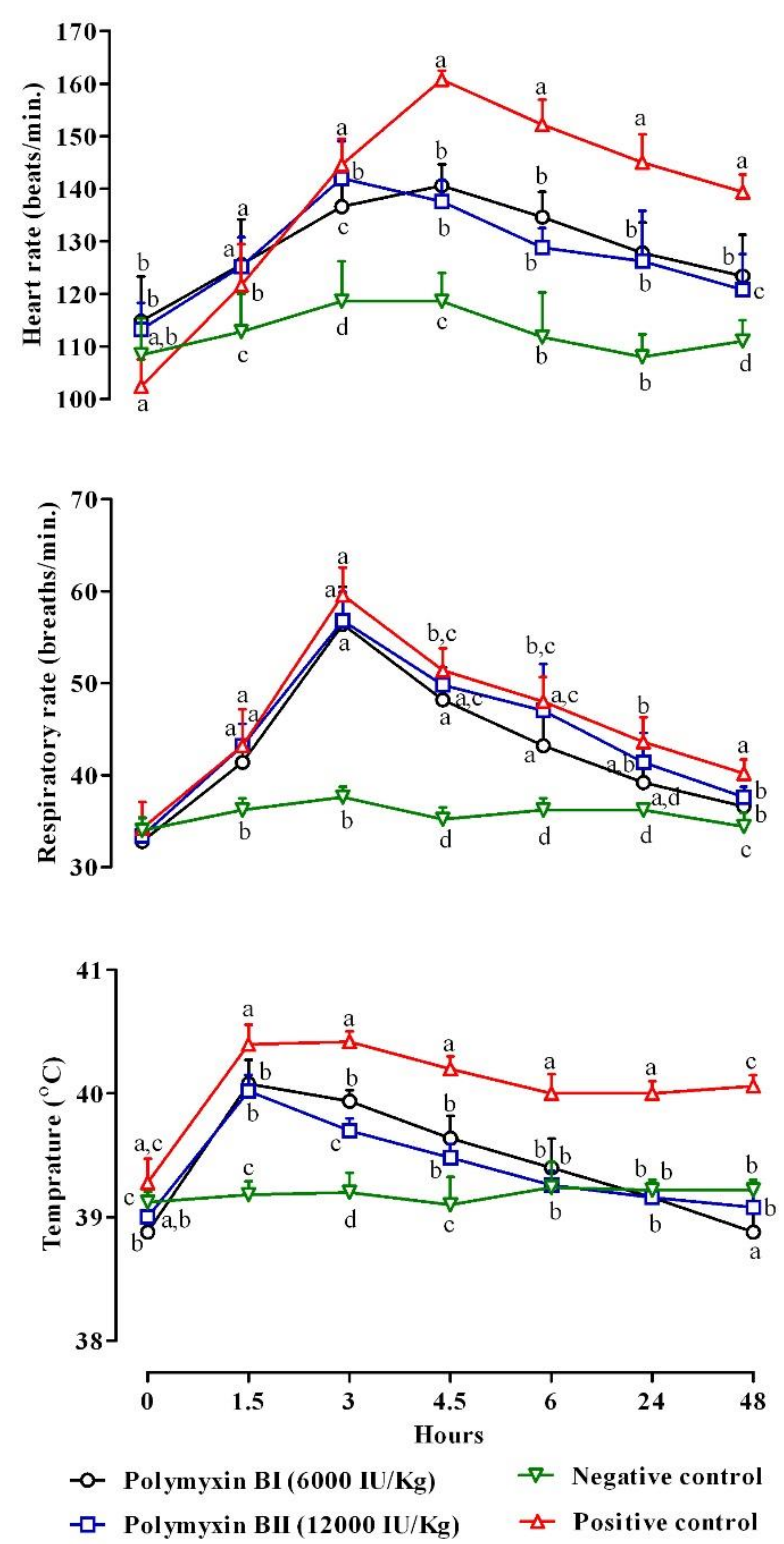

Fig. 1. Clinical parameters (mean $\pm \mathrm{SD}$ ) at different hours after intravenous LPS administration and in all experimental groups.

Different letters indicate significant difference among groups $(\mathrm{P}<0.05)$
Heart rate, respiratory rate, and rectal temperature all increased significantly after LPS infusion in all LPStreated groups. The increase in respiratory rate after LPS administration was obvious in all groups, with the exception of the negative control group. The values of vital signs returned to almost normal after $24 \mathrm{~h}$ in polymyxin B groups. In the polymyxin BI group, rectal temperature was significantly lower than that of the other endotoxin-treated groups at $\mathrm{h} 48(\mathrm{P}<0.05)$ (Fig. 1). Rectal temperature was significantly different between polymyxin B groups at hours 3 and $48(\mathrm{P}<0.05)$ (Fig. 1). The trend change of rectal temperature in both treatment groups altered significantly at different times (Fig. 1). After LPS injection at hour 1.5, respiratory rates in the polymyxin B groups significantly increased as compared with those of the negative control group $(\mathrm{P}<0.05)$. Significant differences in respiratory rates were not observed between the polymyxin B groups at the different denoted times. However, respiratory rates of positive controls and the polymyxin BI group were significantly different at 4.5, 6, 24, and $48 \mathrm{~h}(\mathrm{P}<0.05)$. The heart rates in the polymyxin BII group were significantly lower at hour 48 than those of other LPStreated groups $(\mathrm{P}<0.05)$ (Fig. 1). Although heart rates in the positive control group had an increasing trend up to $4.5 \mathrm{~h}$ and subsequently decreased, they were still higher at hour 48 in comparison with hour 0 . There were no significant differences in heart rates between polymyxin B groups, with the exception of hours 3 and $48(\mathrm{P}<0.05)$. The trend change of heart rate in the positive control group significantly altered during the study at different times (Fig. 1).

TNF- $\alpha$. Serum concentrations of TNF- $\alpha$ in the experimental groups at different times are presented in Table 1. No significant changing pattern was observed in the negative control group. The concentration of TNF- $\alpha$ increased rapidly after LPS administration in all experimental groups except the negative control group. Rapid elevations of TNF- $\alpha$ were observed and they were significantly different between hour 0 and the first time after endotoxin infusion $(\mathrm{P}<0.05)$. After LPS administration in the positive control group, serum concentrations of TNF- $\alpha$ elevated significantly up to $48 \mathrm{~h}$ and the trend of the changes was significant (Table 3), while the rate of increase in serum concentrations of TNF- $\alpha$ in the polymyxin B-treated groups presented a declining trend. Statistically significant differences in TNF- $\alpha$ concentration were observed separately between the polymyxin B and positive control groups from hour 3 to 48 after LPS administration. However, in this regard there were no significant differences between the polymyxin BI and polymyxin BII groups $(\mathrm{P}>0.05)$.

Haptoglobin. Serum concentrations of $\mathrm{Hp}$ at different times in each of the experimental groups are presented in Table 1. The concentrations elevated rapidly after LPS administration in all experimental groups $(\mathrm{P}<0.05)$, with the exception of the negative control group. There was no significant changing pattern in the negative control group (Table 1). The highest serum 
Table 1. TNF- $\alpha, \mathrm{Hp}$, and lactate concentrations (mean $\pm \mathrm{SD})$ at different hours after intravenous LPS administration in all experimental groups

\begin{tabular}{|c|c|c|c|c|c|c|c|c|}
\hline \multirow{2}{*}{ Parameters } & \multirow{2}{*}{ Groups } & \multicolumn{7}{|c|}{ Hours } \\
\hline & & 0 & 1.5 & 3 & 4.5 & 6 & 24 & 48 \\
\hline \multirow{4}{*}{$\begin{array}{l}\text { TNF- } \alpha \\
(\mathrm{ng} / \mathrm{L})\end{array}$} & Negative control & $169 \pm 85$ & $178 \pm 79$ & $183 \pm 77^{\text {ac }}$ & $179 \pm 79^{\mathrm{a}}$ & $182 \pm 83^{\mathrm{a}}$ & $184 \pm 85^{\mathrm{a}}$ & $190 \pm 85^{\mathrm{a}}$ \\
\hline & Positive control & $178 \pm 31$ & $223 \pm 57$ & $270 \pm 37^{\mathrm{b}}$ & $325 \pm 16^{\mathrm{b}}$ & $337 \pm 10^{\mathrm{b}}$ & $336 \pm 13^{b}$ & $325 \pm 14^{\mathrm{b}}$ \\
\hline & Polymyxin BI & $169 \pm 50$ & $186 \pm 47$ & $191 \pm 51^{\mathrm{a}}$ & $202 \pm 53^{\mathrm{a}}$ & $191 \pm 55^{\mathrm{a}}$ & $183 \pm 50^{\mathrm{a}}$ & $180 \pm 48^{\mathrm{a}}$ \\
\hline & Polymyxin BII & $168 \pm 25$ & $182 \pm 21$ & $199 \pm 38^{\mathrm{ab}}$ & $233 \pm 63^{\mathrm{a}}$ & $213 \pm 36^{\mathrm{a}}$ & $200 \pm 20^{\mathrm{a}}$ & $194 \pm 15^{\mathrm{a}}$ \\
\hline \multirow{4}{*}{$\begin{array}{l}\mathrm{Hp} \\
(\mathrm{mg} / \mathrm{L})\end{array}$} & Negative control & $232 \pm 11$ & $242 \pm 14$ & $246 \pm 23^{a}$ & $253 \pm 21^{\mathrm{c}}$ & $259 \pm 29^{c}$ & $253 \pm 33^{c}$ & $253 \pm 34^{c}$ \\
\hline & Positive control & $254 \pm 33$ & $301 \pm 32$ & $395 \pm 50^{c}$ & $448 \pm 39^{b}$ & $524 \pm 44^{\mathrm{b}}$ & $565 \pm 19^{b}$ & $589 \pm 14^{b}$ \\
\hline & Polymyxin BI & $248 \pm 51$ & $300 \pm 100$ & $330 \pm 113^{\mathrm{ac}}$ & $374 \pm 130^{\mathrm{a}}$ & $397 \pm 141^{\mathrm{a}}$ & $439 \pm 142^{\mathrm{a}}$ & $442 \pm 150^{\mathrm{a}}$ \\
\hline & Polymyxin BII & $261 \pm 38$ & $282 \pm 50$ & $299 \pm 49^{\mathrm{a}}$ & $312 \pm 56^{\mathrm{ac}}$ & $327 \pm 65^{\mathrm{ac}}$ & $339 \pm 68^{\mathrm{ac}}$ & $362 \pm 83^{\mathrm{ac}}$ \\
\hline \multirow{4}{*}{$\begin{array}{l}\text { Lactate } \\
(\mathrm{g} / \mathrm{L})\end{array}$} & Negative control & $0.67 \pm 0.01$ & $0.90 \pm 0.01^{\mathrm{b}}$ & $1.23 \pm 0.02^{\mathrm{a}}$ & $1.33 \pm 0.03^{\mathrm{c}}$ & $1.35 \pm 0.01^{\mathrm{a}}$ & $1.03 \pm 0.01^{\mathrm{a}}$ & $0.65 \pm 0.01^{\mathrm{b}}$ \\
\hline & Positive control & $0.63 \pm 0.01$ & $0.68 \pm 0.01^{\mathrm{b}}$ & $2.51 \pm 0.03^{\mathrm{b}}$ & $3.50 \pm 0.04^{\mathrm{b}}$ & $4.30 \pm 0.01^{\mathrm{c}}$ & $1.80 \pm 0.04^{\mathrm{b}}$ & $0.80 \pm 0.01^{\mathrm{bc}}$ \\
\hline & Polymyxin BI & $0.74 \pm 0.01$ & $1.21 \pm 0.03^{\mathrm{a}}$ & $1.12 \pm 0.06^{\mathrm{a}}$ & $2.06 \pm 0.02^{\mathrm{a}}$ & $2.10 \pm 0.07^{\mathrm{a}}$ & $1.15 \pm 0.01^{\mathrm{a}}$ & $1.10 \pm 0.03^{\mathrm{ac}}$ \\
\hline & Polymyxin BII & $0.59 \pm 0.01$ & $0.65 \pm 0.01^{b}$ & $1.51 \pm 0.04^{\mathrm{a}}$ & $2.48 \pm 0.05^{\mathrm{a}}$ & $3.15 \pm 0.08^{\mathrm{b}}$ & $1.70 \pm 0.02^{\mathrm{b}}$ & $1.30 \pm 0.02^{\mathrm{a}}$ \\
\hline
\end{tabular}

Different letters in each column indicate significant difference $(\mathrm{P}<0.05)$

Table 2. $\mathrm{P}$ value of trend change of each parameter in separate groups from hour 0 to hour 48

\begin{tabular}{lllllll}
\hline \multirow{2}{*}{ Groups } & \multicolumn{7}{c}{ Parameters } \\
\cline { 2 - 7 } & $\mathrm{Hp}$ & TNF- $\alpha$ & Lactate & Heart rate & Respiratory rate & Temperature \\
\hline Negative control & 0.213 & 0.294 & 0.093 & 0.4 & 0.942 & 0.165 \\
Positive control & $0.001 *$ & $0.002^{*}$ & $0.001^{*}$ & $0.001^{*}$ & 0.287 & 0.049 \\
Polymyxin BI & $0.01 *$ & 0.071 & 0.021 & 0.03 & 0.249 & $0.012^{*}$ \\
Polymyxin BII & $0.009 *$ & 0.146 & $0.001^{*}$ & 0.566 & 0.888 & $0.001^{*}$ \\
\hline
\end{tabular}

* Stars indicate significant trend change for each parameter in different groups $(\mathrm{P}<0.05)$.

In this table the time is considered as a covariable

concentrations of $\mathrm{Hp}(589 \pm 14 \mathrm{mg} / \mathrm{L})$ occurred at hour 48 after injection of LPS in the positive control group. Serum concentrations of $\mathrm{Hp}$ at different times in polymyxin B groups were significantly lower than those of the positive control group. Significant differences were generally found between hour 3 and hour $48(\mathrm{P}<0.05)$. There were no significant differences between $\mathrm{Hp}$ concentrations in the two polymyxin B groups (Table 1). $\mathrm{Hp}$ increased significantly in the positive control and both treatment groups in different times (Table 2).

Lactate. In all experimental groups, with the exception of negative control group, serum concentrations of lactate at the first time after LPS administration were significantly higher than the basis line concentrations at hour $0(\mathrm{P}<0.05)$ (Table 1$)$. Blood lactate concentrations increased after LPS administration in the positive control group up to $6 \mathrm{~h}$ and subsequently declined after $48 \mathrm{~h}$. The trend change of lactate increased significantly in the positive control group at different times (Table 2). In comparison with the positive control group, the polymyxin BI group revealed a significant reduction of plasma lactate concentration at different times. It is obvious that the polymyxin BI group's dose was able to restrain elevated concentrations of blood lactate. Although a statistically significant difference was noticed between the polymyxin groups at hour 6 and 24, it seems that the polymyxin BI dose had a better impact on reducing blood lactate concentrations than that of the polymyxin BII group (Table 1).

\section{Discussion}

LPS is the major part of the outer membrane of Gram-negative bacteria and is released when bacteria die or multiply. This process results in extreme production and liberation of inflammatory cytokines and subsequent adverse effects $(3,22)$. Current therapies suggested for Gram-negative sepsis and septic shock involve utilisation of antibiotics to control the infection, and intensive care support to correct the underlying dysfunctions of the circulatory and ventilatory systems, and other organ systems. The present experimental study was designed to assess the anti-endotoxic impacts of polymyxin B in an ovine model. The clinical effects of various anti-inflammatory drugs on clinical manifestations of experimentally-induced endotoxaemia in sheep have been investigated in several studies $(5,23$, $24,33,34)$. In the present study, heart and respiratory rates and rectal temperature significantly increased following LPS administration in sheep. These clinical variables improved following polymyxin B administrations $(6,000$ and $12,000 \mathrm{U} / \mathrm{kg})$ at different sampling periods. In two studies respectively addressing anti-inflammatory effects of dimethyl sulfoxide and pentoxifylline, it was found that these drugs had significant improving effects on rectal temperature and respiration and heart rates $(23,24)$. Wong et al. (33) reported the clinical efficacy of polymyxin $\mathrm{B}$ on experimentally-induced endotoxaemia in a group of foals and confirmed that polymyxin B improved clinical symptoms following injection of endotoxin. Van Miert et al. (29) studied the effects of polymyxin B on the acute phase response to Escherichia coli endotoxin in dwarf goats and found that pretreatment with polymyxin B significantly reduced body temperature, heart rate, and rumen motility. Infusion of polymyxin B alone caused tachycardia and inhibition of ruminal contraction in goats.

TNF- $\alpha$ is considered to be the most important proinflammatory cytokine $(2,3)$. Research addressing the 
pathogenesis of endotoxaemia points to TNF- $\alpha$ as a dominant mediator of endotoxicity (31). In the present study, significant and rapid elevation of serum TNF- $\alpha$ concentration was observed before commencing intravenous fluid therapy in all endotoxin-treated groups. Infusion of polymyxin B was followed by marked and significant depression of serum concentration of TNF- $\alpha$ in polymyxin B groups compared with the positive control group. There were no significant differences between polymyxin B groups in terms of decreasing the concentrations of TNF- $\alpha$. Increased serum concentration of TNF- $\alpha$ in response to endotoxaemia in sheep has been studied previously $(6,24)$. Parviainen et al. (17) used polymyxin B in treatment of experimentally-induced endotoxaemia in horses. They reported the dose-dependent effects of polymyxin $\mathrm{B}$ in doses of 1,100 and $5,200 \mathrm{U} / \mathrm{kg}$ in inhibiting effects of TNF- $\alpha$. It was found that $3 \mathrm{~h}$ after polymyxin $\mathrm{B}$ injection, almost $75 \%$ of TNF- $\alpha$ activity decreased. MacKay et al. (13) stated that utilisation of polymyxin B (polymyxin B-dextran 70) in horses at a dose of $5,000 \mathrm{U} / \mathrm{kg}$ after injection of LPS caused a significant reduction in serum concentrations of TNF- $\alpha$ and IL- 6 and reduced heart and respiration rates, as well as rectal temperature. The promising effects of using polymyxin $\mathrm{B}$ in intestinal strangulation injuries, pleuropneumonia, and postpartum metritis have been studied on adult horses (28). After an experimental induction of endotoxaemia in foals (single dose of $0.5 \mu \mathrm{g}$ LPS $/ \mathrm{kg}$ ), slow intravenous injection of polymyxin $\mathrm{B}(6,000 \mathrm{U} / \mathrm{kg})$ resulted in a significant reduction of serum concentration of TNF- $\alpha$ and improvement of the clinical symptoms of endotoxaemia (33). The release of endotoxin in the blood stream is considered to be a stimulus for synthesis of acute-phase proteins (APPs) and inflammatory mediators. Due to the relatively short half-life of acute-phase proteins in the blood and the rapid response of APPs in sick animals, they can be considered to be a measure of animal health (7). In comparison with haematology and clinical tests, determination of acute-phase proteins for the diagnosis of various infectious diseases provides more sensitive results. APPs increase during the development of systemic inflammatory response syndrome and decrease in the recovery stages of inflammatory conditions (16). Acute-phase proteins, notably haptoglobin, and their alterations have been studied widely due to inflammatory and non-inflammatory conditions in various animal species including sheep $(15,25) . \mathrm{Hp}$ along with other APPs has been suggested as a marker of stress in animals (18). In ruminants, the concentration of circulating $\mathrm{Hp}$ is insignificant in healthy animals; however, it rises over 100-fold with immune stimulation (32). Additionally, $\mathrm{Hp}$ is a clinically useful variable for assessing the occurrence and severity of inflammatory diseases in sheep (25). In this research, the observed rapid meaningful rise in serum concentrations of $\mathrm{Hp}$ occurred in all sheep after $48 \mathrm{~h}$ following endotoxin infusion. This result agrees with experimentally induced endotoxaemia in Iranian fat-tailed sheep where haptoglobin concentration significantly increased $48 \mathrm{~h}$ after infusion of endotoxin (23).

Although administration of polymyxin B decreased serum haptoglobin concentrations, there were no significant differences between the 6,000 and 12,000 U/kg groups in this regard. An increase in blood lactate concentrations occurred after LPS administration. It has been reported that blood lactate concentrations increased in the cases of sepsis and were frequently observed as the evidence of tissue hypoxia and/or lack of oxygen secondary to hypoperfusion (26). Acute circulatory failure and poor oxygenation of blood (e.g. hypotension) which occur after septic shock can cause development of lactic acidosis or underutilisation of lactate (11). As the shock progresses, metabolic acidosis aggravates and blood $\mathrm{pH}$ decreases. Hyperlactatemia is a marker of disease severity and a strong predictor of mortality (12). In a group of rabbits with experimentally induced endotoxaemia, serum lactate concentration increased following the injection of LPS of Escherichia coli (10). In the present study, the effect of polymyxin B on serum lactate concentration in fat-tailed sheep after LPS administration was found to be dose-dependent. In comparison with the positive control group, the polymyxin BI group $(6,000 \mathrm{U} / \mathrm{kg})$ experienced a significantly reduced blood lactate concentration. Wong et al. (33) reported similar findings in neonatal foals treated with intravenous administration of polymyxin B after a challenge with experimental endotoxaemia. Yamamoto et al. (35) evaluated the effect of direct haemoperfusion (DHP) (using polymyxin B-immobilised fibres as an extrapectorial blood filter) on endotoxaemic anaesthetised sheep and reported that it improved shock and deteriorated oxygenation during endotoxaemia, probably through the suppression of nitric oxide production. Van Miert et al. (29) established that most of the haematological and blood biochemical effects of Escherichia coli LPS can be reduced by polymyxin B pretreatment in dwarf goats.

Polymyxin B is a cationic, polypeptide antibiotic which possesses bactericidal activity against gramnegative bacteria. It has an extra advantage of binding to lipid A LPS and interacts with the lipid A-keto-3deoxyoctulosonate region of the LPS molecule by forming inactive polymyxin B-LPS complexes (29). Although a number of anti-endotoxin proteins and peptides have been reported $(1,9,21,29)$, there is still no anti-endotoxin agent certified for clinical use in endotoxaemia in sheep.

In conclusion, polymyxin $\mathrm{B}$ acts as an antiendotoxic drug by attenuating the acute-phase response following LPS administration via binding the circulating endotoxins. Based on the results of the present research, pro-inflammatory cytokine (TNF- $\alpha$ ) and proinflammatory hepatic APP (Hp) decreased following polymyxin $\mathrm{B}$ infusion at different doses after Escherichia coli serotype O55:B5 LPS administration in Iranian fat-tailed sheep. According to our results, 
polymyxin B did not induce its effects in a dosedependent manner and its anti- and pro-inflammatory effects at 6,000 and $12,000 \mathrm{U} / \mathrm{kg}$ doses were statistically similar except in lactate concentration, which reduced more in polymyxin $\mathrm{B}$ at $6,000 \mathrm{U} / \mathrm{kg}$. Finally, it may be suggested that polymyxin B could be used as an antiendotoxic drug against endotoxaemia in Iranian fattailed sheep. However, further investigations including prospective clinical trials may be required to confirm the role of polymyxin B in treatment of farm animal endotoxaemia. The results of the present study may suggest a new potential therapeutic regimen for endotoxaemia in small ruminant medicine.

Conflict of Interests Statement: The authors declare that there is no conflict of interests regarding the publication of this article.

Financial Disclosure Statement: This study was financed by a $\mathrm{PhD}$ student project grant by the School of Veterinary Medicine, Shiraz University, Shiraz, Iran.

Animal Rights Statement: The present experiment on animals was performed after being approved by the Ethics Committee laws and regulations of the School of Veterinary Medicine, Shiraz University, Iran, as regards care and use of experimental animals.

\section{References}

1. Bergen P.J., Li J., Rayner C.R., Nation R.L.: Colistin methanesulfonate is an inactive prodrug of colistin against Pseudomonas aeruginosa. Antimicrob Agents Chemother 2006, 50, 1953-1958.

2. Beutler B.: Innate immune responses to microbial poisons: discovery and function of the Toll-like receptors. Annu Rev Pharmacol Toxicol 2003, 43, 609-628.

3. Beutler B., Cerami A.: Tumor necrosis, cachexia, shock, and inflammation: a common mediator. Ann Rev Biochem 1988, 57, 505-518.

4. Cardoso L.S., Araujo M.I., Góes A.M., Pacífico L.G., Oliveira R.R., Oliveira S.C.: Polymyxin B as inhibitor of LPS contamination of Schistosoma mansoni recombinant proteins in human cytokine analysis. Microb Cell Fact 2007, 6, 1-6.

5. Chalmeh A., Badiei K., Pourjafar M., Nazifi S.: Acute phase response in experimentally Escherichia coli serotype O55: B5 induced endotoxemia and its comparative treatment with dexamethasone and flunixin meglumine in Iranian fat-tailed sheep. Vet Arh 2013, 83, 301-312.

6. Chalmeh A., Badiei K., Pourjafar M., Nazifi S.: Modulation of inflammatory responses following insulin therapy in experimentally bolus intravenous Escherichia coli lipopolysaccharide serotype O55: B5 induced endotoxemia in Iranian fat-tailed sheep. Small Rumin Res 2013, 113, 283-289.

7. Eckersall P., Bell R.: Acute phase proteins: Biomarkers of infection and inflammation in veterinary medicine. Vet $\mathrm{J} 2010$, 185, 23-27.

8. Ertmer C., Kampmeier T.G., Rehberg S., Morelli A., Köhler G., Lange M., Pinto B.B., Höhn C., Hahnenkamp K., Van Aken H., Westphal M.: Effects of balanced crystalloid vs. $0.9 \%$ salinebased $v s$. balanced $6 \%$ tetrastarch infusion on renal function and tubular integrity in ovine endotoxemic shock. Crit Care Med 2011, 39, 783-792.
9. Gough M., Hancock R., Kelly N.M.: Antiendotoxin activity of cationic peptide antimicrobial agents. Infect Immun 1996, 64 4922-4927.

10. Hurtado F.J., Gutierrez A.M., Silva N., Fernandez E., Khan A.E., Gutierrez G.: Role of tissue hypoxia as the mechanism of lactic acidosis during E. coli endotoxemia. J Appl Physiol 1992, 72, 1895-1901.

11. Kelley D.M.: Hypovolemic shock: an overview. Crit Care Nurs Q 2005, 28, 2-19.

12. Kruse O., Grunnet N., Barfod C.: Blood lactate as a predictor for in-hospital mortality in patients admitted acutely to hospital: a systematic review. Scand J Trauma Resusc Emerg Med 2011, 19, 74-86.

13. Mackay R., Clark C., Logdberg L., Lake P.: Effect of a conjugate of polymyxin B-dextran 70 in horses with experimentally induced endotoxemia. Am J Vet Res 1999, 60, 68-75.

14. Morresey P.R., Mackay R.J.: Endotoxin-neutralizing activity of polymyxin B in blood after IV administration in horses. Am J Vet Res 2006, 67,642-647.

15. Murata $\mathrm{H}$ : Stress and acute phase protein response: an inconspicuous but essential linkage. Vet J 2007, 173, 473-474.

16. Nazifi S., Khoshvaghti A., Gheisari H.: Evaluation of serum and milk amyloid A in some inflammatory diseases of cattle. Iran J Vet Res 2008, 9, 222-226.

17. Parviainen A.K., Barton M.H., Norton N.N.: Evaluation of polymyxin $\mathrm{B}$ in an ex vivo model of endotoxemia in horses. Am J Vet Res 2001, 62, 72-76.

18. Pineiro M., Pineiro C., Carpintero R., Morales J., Campbell F.M., Eckersall P.D., Toussaint M.J., Lampreave F.: Characterisation of the pig acute phase protein response to road transport. Vet J 2007, 173, 669-674.

19. Pristovšek P., Kidric J.: Solution structure of polymyxins B and E and effect of binding to lipopolysaccharide: an NMR and molecular modeling study. J Med Chem 1999, 42, 4604-4613.

20. Radostists O.M., Gay C.C., Hinchcliff K.W., Constable P.D: Diseases associated with bacteria. In: Veterinary Medicine, edited by W.B. Saunders, London, 2007, pp. 1094-1123.

21. Ried C., Wahl C., Miethke T., Wellnhofer G., Landgraf C., Schneider-Mergener J., Hoess A.: High affinity endotoxinbinding and neutralizing peptides based on the crystal structure of recombinant Limulus anti-lipopolysaccharide factor. J Biol Chem 1996, 271, 28120-28127.

22. Rosenstreich D., Vogel S.: Central role of macrophages in the host response to endotoxin. Microbiology, 1980, 1980, 11-15.

23. Samimi A., Hajimohammadi A., Fazeli M., Nazifi S.: Effect of dimethyl sulfoxide on clinical signs and acute phase proteins during endotoxemia induced by Escherichia coli serotype O55:B5 in sheep. Online J Vet Res 2014, 18, 188-200.

24. Shahraki A.R., Pourjafar M., Chalmeh A., Badiei K., Heidari S., Zamiri M., Nazifi S.: Attenuating the endotoxin induced acute phase response by pentoxifylline in comparison with dexamethasone and ketoprofen in sheep. Small Rumin Res 2016, $136,156-160$

25. Skinner J., Roberts L.: Haptoglobin as an indicator of infection in sheep. Vet Rec 1994, 134, 33-36.

26. Sterling S.A., Miller W.R., Pryor J., Puskarich M.A., Jones A.E.: The impact of timing of antibiotics on outcomes in severe sepsis and septic shock: a systematic review and meta-analysis. Crit Care Med 2015, 43, 1907-1915.

27. Steverink P., Sturk A., Rutten V., Wagenaar-Hilbers J., Klein W., Van der Velden M., Nemeth F.: Endotoxin, interleukin-6, and tumor necrosis factor concentrations in equine acute abdominal disease: relation to clinical outcome. J Endotoxin Res 1995, 2, 289-299.

28. Sykes B., Furr M.: Equine endotoxaemia-A state-of-the-art review of therapy. Aust Vet J 2005, 83, 45-50.

29. Van Miert A.S., Van Duin C.T., Wensing T.: Effects of pentoxifylline and polymyxin $\mathrm{B}$ on the acute-phase-response to Escherichia coli endotoxin in dwarf goats. J Vet Pharmacol Ther 1997, 20, 61-68 
30. Vassalli P.: The pathophysiology of tumor necrosis factors. Annu Rev Immunol 1992, 10, 411-452.

31. Weiss D.J., Wardrop K.J.: Schalm's veterinary hematology, John Wiley \& Sons, Philadelphia, 2011.

32. Werners A., Bull S., Fink-Gremmels J.: Endotoxaemia: a review with implications for the horse. Equine Vet J 2005, 37, 371-383.

33. Wong D.M., Sponseller B.A., Alcott C.J., Agbedanu P.N., Wang C., Hsu W.H.: Effects of intravenous administration of polymyxin B in neonatal foals with experimental endotoxemia. J Am Vet Med Assoc 2013, 243, 874-881.
34. Wynn J.L., Wong H.R.: Pathophysiology and treatment of septic shock in neonates. Clin Perinatal 2010, 37, 439-479.

35. Yamamoto H., Koizumi T., Kaneki T., Fujimoto K., Kubo K. Honda T.: Direct hemoperfusion with polymyxin B-immobilized fiber improves shock and hypoxemia during endotoxemia in anesthetized sheep. J Endotoxin Res 2002, 8, 419-426.

36. Young L., Glauser M.: Gram-negative septicemia and septic shock. WB Saunders, Philadelphia, 1991. 